\title{
Mulheres em Situação de Abortamento: estudo de caso'
}

Women in Abortion situation: a case study

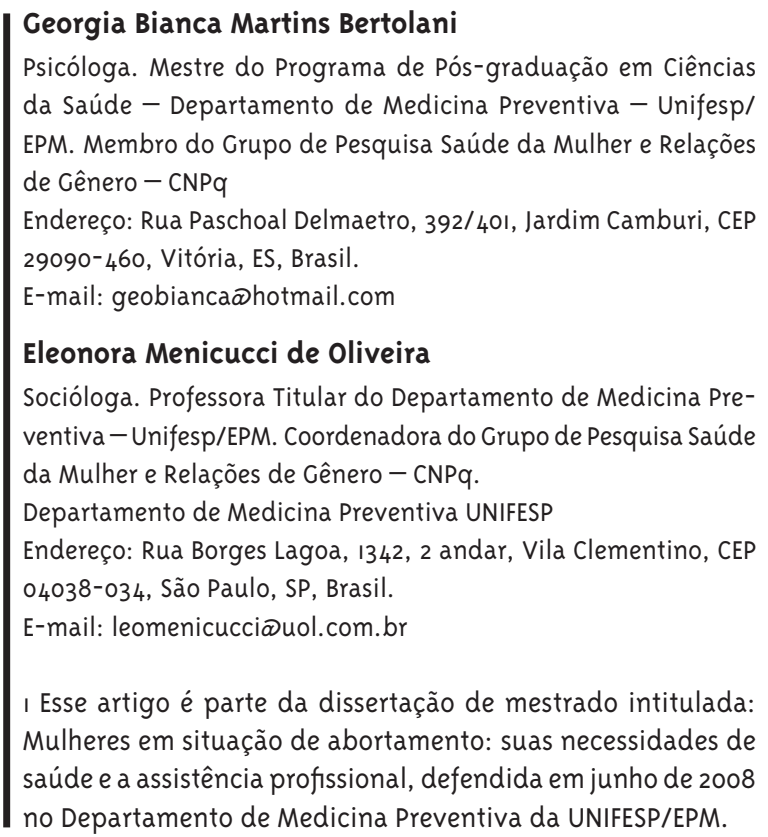

Psicóloga. Mestre do Programa de Pós-graduação em Ciências da Saúde - Departamento de Medicina Preventiva - Unifesp/ EPM. Membro do Grupo de Pesquisa Saúde da Mulher e Relações de Gênero - CNPq

Endereço: Rua Paschoal Delmaetro, 392/40I, Jardim Camburi, CEP 29090-460, Vitória, ES, Brasil.

E-mail: geobiancaœhotmail.com

Eleonora Menicucci de Oliveira

Socióloga. Professora Titular do Departamento de Medicina Preventiva - Unifesp/EPM. Coordenadora do Grupo de Pesquisa Saúde da Mulher e Relações de Gênero - CNPq.

Departamento de Medicina Preventiva UNIFESP

Endereço: Rua Borges Lagoa, 1342, 2 andar, Vila Clementino, CEP 04038-034, São Paulo, SP, Brasil.

E-mail: leomenicucci®uol.com.br

I Esse artigo é parte da dissertação de mestrado intitulada: Mulheres em situação de abortamento: suas necessidades de saúde e a assistência profissional, defendida em junho de 2008 no Departamento de Medicina Preventiva da UNIFESP/EPM.

\section{Resumo}

Este trabalho pretende, por meio da abordagem qualitativa e a partir de estudo de caso, analisar as narrativas de 19 mulheres em situação de abortamento, que foram atendidas no Hospital da Universidade Federal do Espírito Santo (Hucam) do município de Vitória. A coleta dos dados foi realizada com o uso de técnicas de observação participante, entrevista com roteiro semiestruturado, registro em diário de campo e análise de prontuário. Os dados se apresentam a partir da construção de narrativas, segundo o modelo proposto por Bourdieu (2003); a análise das entrevistas gravadas seguiu a orientação de Pope e colaboradores (2006), com a consequente construção de categorias empíricas emergentes das narrativas. As categorias emergentes das narrativas das mulheres foram divididas em quatro: as experiências reprodutivas; como as mulheres perceberam-se grávidas; a experiência do abortamento; e o atendimento nos serviços de saúde. Os resultados demonstraram que a assistência não contempla suas necessidades de saúde, nem respeita seus direitos reprodutivos. Elas caracterizam o atendimento como ruim, ineficiente, preconceituoso, independentemente de terem provocado ou não o abortamento.

Palavras-chave: Abortamento; Necessidades de saúde; Assistência. 


\section{Abstract}

This research intends to analyze, through a qualitative approach and a case study, the narratives of 19 women in abortion situation, who were assisted in the HUCAM (Hospital of the Federal University) of the city of Vitoria, state of Espírito Santo. The data collection was made through participative observation techniques, semi-structured interviews, registrations on a field notebook and analysis of the women's medical records. The data were presented through the construction of narratives, following the model proposed by Bourdieu (2003); the analysis of the recorded interviews followed the orientation of Pope et al. (2006), with the construction of empiric categories that emerged from the narratives. Four categories emerged from the women's narratives: reproductive experiences; how women perceived the pregnancy; the abortion experience; and the provided healthcare services. The results demonstrate that the provided assistance neither meets their health needs nor respects their reproductive rights. The interviewed women, both the ones who caused the abortion or those who had a miscarriage, characterize the service as bad, inefficient and prejudicial.

Keywords: Abortion; Health Needs; Assistance.

\section{Introdução}

Trata-se de uma pesquisa qualitativa (Cortes, 1998) que a partir do estudo de caso (Lüdke e André, 1986; Becker, 1999) analisou as narrativas de 19 mulheres em situação de abortamento, que foram internadas na enfermaria de obstetrícia do Hospital da Universidade Federal do Espírito Santo (Hucam) na cidade de Vitória - ES, para a realização de curetagem após abortamento.

Os objetivos foram apreender: a assistência prestada pela equipe de saúde às mulheres em situação de abortamentos espontâneo e provocado que buscaram atendimento e/ou foram internadas nesse hospital público, bem como a percepção do atendimento por parte das mulheres atendidas e/ou internadas.

A coleta dos dados foi realizada com o uso de técnicas de observação participante (Cicourel, 1990), entrevista com roteiro semiestruturado (Thiollent, 1980; Queiroz, 1991; Oliveira e col., 2005), registro em diário de campo (Queiroz, 1991) e análise de prontuário. Nenhuma das mulheres abordadas negou sua participação no estudo ou solicitou retirada de suas informações.

Os dados foram analisados a partir da orientação de Pope e Mays (2006), construindo quatro categorias empíricas emergentes das entrevistas: as experiências reprodutivas; como as mulheres perceberam-se grávidas; a experiência do abortamento; e o atendimento nos serviços de saúde.

$\mathrm{O}$ fato de o abortamento ser um tema complexo aponta que a assistência às mulheres nessa situação demanda integralidade nas ações de saúde que se iniciam desde as experiências reprodutivas, contraceptivas até o exercício da autonomia - ter ou não ter aquele filho ou filha.

A experiência do abortamento é muitas vezes estigmatizada por alguns setores sociais que se colocam contrários a essa prática, e afirmam que é uma experiência que fica negativamente marcada na vida da mulher. Algumas pesquisas (Oliveira e col., 1997; Oliveira²) relatam que as mulheres, depois de um abortamento, sofrem sintomas compatíveis com o estresse pós-traumático. Observamos em nosso

2 OLIVEIRA, E. M. (Coord.). O atendimento ao aborto: um estudo qualitativo. São Paulo, 2008. (Relatório técnico de pesquisa). Não publicado. 
estudo que essa sintomatologia não é causada pela necessidade de interromper a gravidez em si, mas, sim, por toda situação que a clandestinidade coloca as mulheres que viveram tal situação. A ilegalidade, ou seja, o rompimento com a norma legal e moral, o medo de morrer, o medo de ser presa, o arrependimento quando se vê diante de uma situação para a qual ela não foi preparada; a experiência da dor física que, na sua fantasia das mulheres, não existiria; o enigma da perda, o fato de não ser acompanhada por ninguém que acolha essa dor, isso, sim, deixa marcas profundas. A solidão, o desamparo, esses elementos ficam registrados de forma muito negativa.

\section{As Experiências Reprodutivas}

Perguntado às mulheres com que regularidade elas procuravam os serviços de saúde, responderam que com certa regularidade nas Unidades Básica de Saúde (UBS) do bairro onde moravam ou trabalhavam, principalmente para tratarem de questões relacionadas ao ciclo gravídico puerperal.

[...] vou de seis em seis meses, para fazer preventivo ou quando acontece alguma coisa comigo assim. Que nem eu tenho que ir agora porque eu tive muitos filhos e vou ver se o médico passa pra mim, como chama mesmo aquela cirurgia que faz quando a gente tem um monte de filhos, para poder fechar um pouco (Lurdes).

Quando perguntado às mulheres se elas tinham informação acerca de métodos que poderiam ser utilizados para evitar a gravidez, informaram terem conhecimento da camisinha, pílula e outras ainda acrescentaram a possibilidade de uso da camisinha feminina, diafragma, DIU.

Eu conheço as pílulas anticoncepcionais via oral, eu conheço as injeções, que podem ser no mês, de três em três meses, eu conheço o DIU, eu conheço o preservativo, masculino e feminino (Elen).

Com relação ao acesso aos métodos contraceptivos, as mulheres relataram facilidade em adquiri-los, seja na UBS, seja quando elas mesmas compravam.

No posto eu sei que eles dão [...] só quem frequenta lá é que pega (Alice).
As mulheres demonstraram que possuíam informação acerca dos programas de saúde. Na época de coleta de dados para esse estudo, o Ministério da Saúde determinou que medicamentos contraceptivos fossem mais bem distribuídos na rede de saúde e vendidos a baixos curtos.

Agora com essa lei que entrou agora vai ser mais fácil, porque que nem antigamente, assim, eu ia no postinho pegar remédio, tinha vez que não tinha e eu não tinha dinheiro para comprar aí eu ficava sem. Que nem esse mês mesmo, eu fiquei dois meses sem tomar injeção, porque agora eu estou tomando injeção, porque remédio eu esqueço. $E$ me parece que desde a segunda-feira passada que o remédio é mais baratinho, aí agora eu já posso comprar, se for mais barato, já dá para mim comprar (Lurdes).

Monteiro e Adesse (2007) e França (1995) afirmam que somente $38 \%$ das mulheres em idade reprodutiva estão teoricamente fora do risco de engravidar. Da parcela dessas, $16 \%$ foram esterilizadas e as outras $22 \%$ utilizam contraceptivos; o restante, ou seja, $62 \%$ das mulheres poderão engravidar.

Faúndes e Barzelatto (2004) afirmam que o número de gestações indesejadas e, consequentemente, o número de abortamentos inseguros diminuiriam se as mulheres tivessem mais acesso ao conhecimento completo, não tutelado pelo Estado, pela igreja nem pela medicina, apropriado e efetivo sobre os meios contraceptivos.

Outra informação que chamou a atenção foi a forma como as mulheres relatavam usar os métodos contraceptivos. Isso sugere que a orientação dada pelo profissional de saúde não atingiu seu objetivo, uma vez que o medicamento era usado de maneira totalmente inadequada.

Eu tinha parado de tomar o anticoncepcional, porque estava me fazendo mal [...]. Enjoo, parecia que eu tava grávida, vontade de vomitar [...] já tinha três meses que eu tinha parado, só que às vezes eu tomava [...] quando eu achava que era o momento, tipo assim, eu ficava menstruada hoje, aí eu esperava o ciclo parar, durante três dias eu tinha relação normal, depois eu tomava (Joice).

Aí, eu imaginei que a injeção não estava fazendo efeito, porque a doutora falou assim: olha, o perí- 
odo que você estiver tomando a injeção, vocên não vai ter sangramento, só que aí começou o contrário, tomava e todo mês certinho a menstruação. Aí eu falei assim, ah, eu vou parar de tomar. Aí parei de tomar e [...] barriga! A doutora falou: não era pravocê ter parado porque esse sangramento ia sumir. Mas aí também antes de eu começar a tomar essa injeção, eu fiquei um bom período sem me prevenir e não engravidei (Janaina).

Outra questão importante: a preocupação maior das mulheres entrevistadas recaía sobre a gravidez. Em nenhuma das 19 entrevistas houve a citação de utilização de métodos contraceptivos de barreira, a fim de se protegerem de doenças sexualmente transmissíveis.

Acerca da procura pelos serviços de saúde, com a finalidade de iniciar o pré-natal, algumas demonstraram resistência, pois ainda não tinham a comprovação da gravidez, ou encontravam-se diante de uma gravidez indesejada.

Não, eu ia fazer, porque todo pré-natal eu sempre enrolo e só começo depois de três meses, que eu ainda acredito que eu não estou [grávida] (Lurdes).

Não, não deu tempo [...] Eu achava que estava muito cedo para fazer exame (Flávia).

Já outras, mesmo não tendo planejado a gravidez, assim que se perceberam grávidas iniciaram imediatamente o acompanhamento.

Comecei no dia seguinte [...] eu procurei uma médica, para que ela iniciasse os exames do procedimento normal do pré-natal. E eu fui atéo Posto Médico. Olha, quando ela pediu os exames, ela já pediu uma ultrassonografia, porque minha barriga estava muito grande, e ela achava que eu já tinha mais de 2 meses, né, então ela ficou preocupada com isso, preocupada também com a possibilidade de ter gêmeos de novo. Aí eu fui, fiz a ultrassom particular mesmo (Elen).

Nos serviços de saúde, os profissionais não questionam se aquela gestação está sendo aceita pela mulher. No Brasil, as mulheres não podem optar por interromper uma gestação que foi resultada de um planejamento contraceptivo inadequado.
Por isso o fato de a mulher não querer levar a gestação adiante não é considerado nem acolhido pelos profissionais da assistência primária. Isso faz com que muitas mulheres, ao perceberem-se grávidas, não busquem diagnosticar efetivamente a presença da gestação e partam para sua interrupção imediata, que é realizada de maneira clandestina, correndo inúmeros riscos, desde a prisão até a morte.

\section{Como as Mulheres Perceberam-se Grávidas}

Todas as mulheres entrevistadas, sem exceção, souberam que estavam grávidas quando perceberam o atraso da menstruação, bem como das alterações corporais. As mulheres que já tinham filhos demonstraram mais facilidade em reconhecer as alterações corporais da gravidez.

Minha menstruação atrasou dois meses e ela não é de atrasar, vem sempre no dia certinho (Flávia).

A gente já sabe, né? [...] aí eu vi os seios começaram a mudar, começou aumentar, enjoo, aí eu falei com ele, ah, estou grávida (Janaina).

Diante da constatação da gestação, os sentimentos desencadeados foram pertinentes ao fato de a gestação estar sendo esperada ou não. As mulheres que estavam planejando a gestação afirmaram que ficaram felizes com a constatação. Em casos onde a mulher não havia planejado a gestação, a acolhida do marido foi um fator que permitiu que ela também ficasse feliz.

Eu me senti bem, o marido gostou, ficamos felizes (Joice).

Desespero, preocupação, choque foram reações que acometeram as mulheres que naquele momento de suas vidas uma gestação não seria bem-vinda, quer por já terem muitos filhos, quer por terem rompido o laço afetivo com o parceiro, quer por não terem condições financeiras, quer por questões de relacionadas à sua própria saúde.

Bem, nem boa e nem ruim, sei lá, dependeria depois como seria quando eu falasse com o pai, porque até então eu não falei nada (Alice). 
Eu fiquei desesperada, porque não queria mais filho, porque assim, a situação que eu me encontrava, era ruim, eu estava com o orgulho ferido, eu estava [...] eu estava muito pra baixo e muito triste, muito magoada (Rafaela).

Foi um choque, para mim desmoronou o mundo, entendeu? Eu não tinha mais nada com ele e inclusive ele já estava com outra pessoa [...] chorei, entrei em depressão, (Helena).

Eu fiquei bem assustada. Bem, porque, eu pensei até em tirar, como estava no começo, depois eu pensei bem e falei não [...] aí eu deixei (Marta).

Toda gravidez tem uma dinâmica psíquica própria, traduzida pela ansiedade ou ambivalência diante da constatação da gestação. Esses conflitos são potencializados em maior ou em menor grau pelo fato de a gravidez, embora não planejada, poder ser aceita ou rejeitada pela mulher; Espírito Santo e Vieira (2007) corroboram que o fato de a gravidez não ser bem-vinda naquele momento pode conduzir ao abortamento. Outros estudos (Oliveira3; Gesteira e col., 2006) também indicaram a existência desses sentimentos diante de uma gestação não planejada.

\section{A Experiência do Abortamento}

Abortamentos espontâneos e provocados são vivenciados de formas diferentes embora sejam ambas as experiências exclusivamente femininas, íntimas, singulares e subjetivas. A forma como cada mulher o vivencia pode ser remetido a outros eventos correlacionados a perdas que já tenham ocorrido em suas vidas.

Num evento espontâneo, o fator inesperado entra, rompendo a sensação de onipotência que o estado da gravidez deixa na mulher. Pode configurar uma ferida narcísea grave, que as leva a sentiremse culpadas pela perda uma vez que a gravidez é vivenciada de forma ambivalente: o desejo e o não desejo de ter aquele filho, quando em situação de abortamento, fazem com que a mulher se sinta como se tivesse "matado" aquele filho (Szejer e Stewart, 2002).
Já nos eventos em que o abortamento é provocado pela mulher, essa sensação de ter "matado" é real e é recheada pelas interferências sociais, religiosas e morais, nas quais a mulher tem de encarar quando decide independentemente do motivo, interromper o estado gravídico.

Neste estudo, notamos que mulheres que já tinham constatado a gestação e que já haviam iniciado o programa de pré-natal, bem como já haviam feito USG, lidaram pior com o evento do abortamento do que aquelas cujos cuidados iniciais não haviam sido iniciados. Isso nos leva a crer que a confirmação da gestação, bem como o uso da tecnologia por meio da imagem do bebê auxiliam na formação do vínculo mãe-bebê (Grigoletti, 2005). Nesses casos, o que se perde não era uma gestação e, sim, um filho em potencial.

Diante da constatação da gravidez essas mulheres se depararam com a pergunta fundamental que provavelmente a maioria faz ao perceber-se grávida: “Manter ou não? Eis a questão!". Esse pensamento ocorre a partir da análise racional do conjunto de situações nas quais as mulheres encontravam-se naquele momento de constatação das gravidezes. O fato de não terem condições financeiras de criar mais um filho naquele momento fez com que cogitassem um abortamento.

Pensar eu pensei, assim como eu pensei em todos os meus filhos, mas coragem eu não tive não, eu morro de medo desses negócios. Eu já tive amigas minhas que já fizeram e que quase morreram, nossa, eu morro de medo (Lurdes).

A reação do parceiro após o anúncio da gravidez também foi um fator muito importante tanto para a manutenção quanto para a supressão da gravidez. Estudos no Brasil acerca da participação masculina tanto dos métodos contraceptivos (Duarte e col., 2002) como na manutenção da gestação são insuficientes (Rodrigues e Hoga, 2005).

No nosso estudo, o homem "aparece" somente no momento em que a mulher lhe comunica a gestação. As reações variaram por diversos motivos. Quando a gravidez fazia parte de um plano comum do casal, a sua constatação deixou o parceiro feliz.

3 OLIVEIRA, E. M. (Coord.). O atendimento ao aborto: um estudo qualitativo. São Paulo, 2005. (Relatório técnico de pesquisa). Não publicado. 
Feliz, né? Que ele queria tanto (Márcia).

Mesmo naqueles casos em que a gestação não estava sendo planejada, mas havia vínculo conjugal estável, a reação do homem também foi positiva.

o meu marido já adorou, já começou a beijar minha barriga e tudo e aí eu fiquei alegre (Janaina).

O vínculo afetivo entre o casal dava de certa forma à mulher a confiança necessária para que ela não abortasse, mesmo diante de adversidades como a situação econômica desfavorável.

Ele disse que onde come três bocas come quatro (Lurdes).

Nas situações onde o relacionamento conjugal havia sido rompido recentemente, a notícia da gravidez deixou os ex-companheiros enfurecidos. Ambos não aceitarem a gravidez e pediram para que elas fizessem um abortamento.

Eu falei com ele, nossa e já sei até o sexo, e ele falou:nãoémeu. Não émeu, não émeu, nãoémeu [...] não quero, não quero de jeito nenhum, você se vira, vou tirar, a gente vai tirar [...] ele estava morando com uma outra mulher. Falou que eu era uma vagabunda, é, me chamou de piranha, safada, que eu estava com outros namorados, tinha outros namorados e estava querendo botar a culpa em cima dele, pra que ele fosse assumir um outro filho que não era dele. [...] quis dizer que o meu filho, o primeiro filho, não era dele. Bem feito pra você, porque agora vocêvai ter uma filha sozinha (Rafaela).

Ele não quis nem saber [chora] [...] Eu conversei com ele [...] e ele não queria saber e eu já tinha as minhas meninas [...] Aí, logo depois a barriga começou a crescer, aí eu fui lá e procurei por ele. Ele já estava morando com outra pessoa. [...] Ele me [...] ele me expulsou da loja. Foi horrivel (Helena).

As narrativas acima demonstram com clareza a situação de abandono na qual fica a mulher diante de uma gestação não planejada e que não terá a "sorte" de dividir as responsabilidades da criação de um filho com o companheiro. A gravidez se dá exclusivamente no corpo das mulheres e são elas que, de uma forma ou de outra, tanto na presença quanto na ausência do companheiro, necessariamente assumem as responsabilidades que uma nova vida traz. Isso evidencia as dificuldades que as mulheres vivenciam devido às questões de gênero, em que elas se tornam total e corporalmente responsáveis pelo resultado do exercício da sua sexualidade.

Perguntamos a todas as mulheres se sabiam o que podia ser usado para não levar uma gravidez adiante. As mulheres citaram um medicamento que é usado para provocar o abortamento. No momento da entrevista, não sabiam nomear o medicamento, ainda assim tinham algum conhecimento de como ele era administrado, embora de maneira equivocada. As mulheres também relataram conhecer outras mulheres que haviam provocado abortamentos, bem como o atendimento prestado a elas em serviços de saúde.

Conheço várias pessoas. [...] tem uma que eu conheço, praticamente é quase minha vizinha, tomou remédio para abortar, veio para cá, aí cuidaram normalmente como se nada tivesse feito [...] mesmo porque, ela contou a verdade (Janaina).

Minha prima [...] tomou um comprimido que coloca na vagina e toma outro (Joice).

Além do uso do Citotec ${ }^{\circledR}$, as mulheres relataram conhecer através da mídia e de experiências de amigas, o uso de chás com o objetivo de regular os atrasos menstruais. Esse conhecimento é passado transgeracionalmente, o evidenciando que as mulheres em todos os tempos conhecem práticas abortivas.

Eu sei que elas tomaram mato, esses negócios amargosos para vim para descer e descia, bem no começo, não com dois meses assim. Eu via muito mesmo o que passava na televisão que tomava remédio mesmo para provocar [...]. Que eu saiba não, só de chá mesmo, que as avós falam que era bom tomar quando a menstruação atrasava.(Lurdes).

Neste estudo, quatro mulheres narraram que tiveram abortamentos provocados. 0 uso do Citotec ${ }^{\circledR}$ foi unânime nos quatro casos.

A clandestinidade faz com que as mulheres que necessitam do medicamento para a indução de um abortamento submetam-se a comprá-lo no "merca- 
do negro”. O Citotec ${ }^{\circledR}$ é vendido de maneira ilegal, muitas vezes o medicamento que é comprado não possui a quantidade necessária da droga capaz de iniciar o processo de abortamento.

E o que ele comprou era falso porque ele comprou seis na primeira tentativa; ele comprou seis, aí não resolveu eu liguei para ele, aí ele comprou mais seis [...]. Tomei e coloquei. Tomei dois e os outros quatro coloquei. No comecinho, eu sentia umas cólicas, até achei que fosse resolver, mas não resolveu. Aí, depois ele comprou mais seis (Helena).

As mulheres que utilizam o medicamento não possuem informações de como será o processo de abortamento. $\mathrm{O}$ início das contrações é catalisado pelo medicamento. As mulheres quando autoadministram a droga se encontram, na maioria das vezes, sozinhas em casa. 0 início das contrações provoca uma sensação mortífera, pois, como não possuem controle sobre seus próprios corpos, e estando sozinhas, essas experiências de aniquilação e total desamparo podem ser impressas na psique dessas mulheres de forma muito singular e, muitas vezes, traumática.

A próxima narrativa relata essa experiência.

Eu acordei com muita cólica, muita cólica [...]. E quando eu acordei, não estava com a calça que eu estava vestida, eu estava sem calça, só de calcinha [...], mas eu não me lembro de ter tirado a calça pra dormir, quando eu deitei aqui na cama, eu passei a madrugada inteira morrendo de dor, não conseguia falar com ninguém, aí eu comecei a ligar pra ele, aí eu falei com ele, o que vocêfez comigo? O que você fez comigo? Eu não fiz nada [...] quando a doutora foi me examinar, ela tirou um [...] resíduos de Citotec dentro de mim, ela falou: Você tentou provocar um aborto? Eu falei, não. Tentou, sim, olha aqui o excesso [...] conseguiu tirar, tipo assim, é como se fosse meio comprimido, dissolvido (Rafaela).

Diante do processo de abortamento, os sentimentos narrados pelas mulheres foram tão variáveis como aqueles desencadeados pela constatação da gestação. Os sentimentos que emergem de uma situação de abortamento devem-se, no caso dos provocados, à total solidão e desamparo em que se encontram as mulheres que necessitam dessa intervenção e que não acham respaldo legal, nem acolhimento social, pois se engana aquele que possa pensar ou acreditar que as mulheres "gostam" de fazer um abortamento. A tomada de decisão é difícil e a execução o é ainda mais. Provocar um abortamento acontece quando a mulher não mais pode considerar as outras opções.

Cada mulher viverá essa experiência de maneira muito particular e que está intimamente ligada a sua história de vida pregressa. Por isso, percebemos com este estudo que é de grande importância escutar essas histórias, reconhecer o lugar que esse filho que não veio ocupava nessa história familiar e dar condições às mulheres de falarem desses filhos e das frustrações provocadas pelo "insucesso" da gravidez.

Outros sentimentos são presentes, como a culpa, que normalmente encobrem um desejo inconsciente de não ter aquele filho (Soifer, 1986; Quayle, 1997; Szejer e Stewart; 2002), bem como a tristeza, a sensação de impossibilidade de gerar uma vida ou de ter outros filhos, sentimento esse recorrente nas primigestas.

Não sei explicar, uma coisa ruim, sei lá [...]. Sei lá, às vezes eu fico me sentindo culpada [...] Eu fiquei até mais abalada do que dessa vez, porque eu estava sentindo umas dores desde o dia todo e dessa vez eu já tava assim, acho que vai acontecer a mesma coisa que aconteceu com o primeiro, aí eu não fiquei tão chateada igual eu fiquei do primeiro (Flávia).

Eu estou com medo de acontecer de novo, eu quero [engravidar novamente] e fico com medo (Márcia).

Para Rafaela e Elen, o sentimento de tristeza foi potencializado. O ex-companheiro de Rafaela havia, a sua revelia, dopado-a e lhe introduzido o medicamento. Outros estudos também indicam a recorrência desse tipo de evento (Oliveira e col., 1997; Oliveira $^{2}$ ). Esse fato configura crime, de acordo com o Código Penal. Rafaela preferiu não denunciá-lo, pois estaria expondo "o pai do seu filho", o que poderia trazer muitas consequências para a criança. Durante a sua entrevista, revelou a pesquisadora que o pai do ex-companheiro é policial e, para preservar a vida, 
decidiu não se manifestar diante da crueldade que o marido fizera. Por isso, não pôde expressar essa experiência e teve de alocá-la, a fim de não exigir a reparação do culpado pela perda da gravidez. Rafaela, mesmo após dois meses do evento, ainda não estava completamente recuperada: apresentava alguns sintomas de Transtorno de Estresse PósTraumático (TEPT).

Eu precisava muito de um psicólogo, eu não estou conseguindo dormir, eu não estou conseguindo relaxar, eu estou muito nervosa, eu estou muito tensa, eu estou muito triste, muito abatida, muito abalada, é [...] tem dia que, que eu estou bem, que eu consigo sair, passear, me divertir, entendeu? $\varepsilon$ tem dia que eu estou pra baixo, eu só quero chorar, que eu quero passar o dia inteiro dormindo, para não ver o dia passar, pra não ver a luz do sol, fecho a casa toda, tranco a casa toda, pra poder não ver ninguém, tem dia que eu não quero falar com ninguém, ouvir a voz de ninguém, eu entro dentro da minha casa, boto o travesseiro no meu ouvido, nem televisão eu não ligo, e [...] eu tento dormir (Rafaela).

Born e colaboradores (2005), em pesquisa de literatura, encontram registros indicando que cerca de $25 \%$ das mulheres que experienciaram a perda do feto até a vigésima semana de gestação podem apresentar altos índices de TEPT, com sintomas tão graves quanto os que se seguem a outros eventos traumáticos. Os autores acrescentam que aproximadamente $1 / 3$ desses casos preencherão também os critérios de depressão maior, cuja recuperação não é imediata, pois quatro meses após a perda, $7 \%$ ainda preenchem os critérios de TEPT. 0 artigo também aponta que há evidências que sugerem um maior risco para outros tipos de transtornos de ansiedade no período de 6 (seis) meses que se seguem a uma perda. Diante dessa realidade, os autores relatam que um maior suporte social pode amortecer o impacto negativo da perda perinatal. Isso sugere que diante de toda transformação trazida por uma gravidez indesejada, que culmina com um abortamento, independentemente de ter sido espontâneo ou provocado pela mulher, muito importante será esta atitude: uma assistência que dê conta não apenas dos cuidados das estruturas fisiológicas, mas, também, de toda alteração psíquica que esses even- tos podem trazer; enfim, isso se faz extremamente necessário para a recuperação total da mulher em situação de abortamento.

Com a perda da gestação atual Elen deparou-se com uma ferida que ainda estava mal curada. Há alguns anos perdera um filho. Pouco após o nascimento dessa criança, foi diagnosticado um câncer, e seis meses após seu nascimento, a criança veio a falecer. Vivenciar novamente uma perda e, principalmente, a perda de mais um filho, fez com que Elen reeditasse o luto mal elaborado da primeira perda.

Posso dizer que eu tenho um pouco de depressão, mas assim, eu guardo muito pra mim, o meu sofrimento; antigamente era exposto, eu sofria e todo mundo via, depois que perdi meu filho, eu sofri, comecei a sofrer pra mim, [pausa], sofria sozinha, [pausa] e com isso, eu endurecimais ainda [pausa], sofri mais sozinha ainda, não deixo transparecer, então pra quem olha pra mim, não vai saber nunca que eu perdi dois filhos (Elen).

A narrativa seguinte traz à luz outra questão. Olívia trabalha como assistente de enfermagem em duas UTIs neonatais, seus afazeres são totalmente direcionados ao cuidado de crianças prematuras e em situação de risco. Após ter vivenciado a experiência da circlagem, feita na tentativa de salvar sua gravidez, o insucesso do procedimento culminou com a indução do abortamento de Olívia. Ela sentiu-se totalmente impossibilitada de retornar à sua atividade laboral. Ao solicitar ao profissional que a assistia há mais tempo para ficar em casa, a resposta foi negativa.

Eu ainda estou tentando lidar com isso. Eu me sinto triste, foi pouco tempo e muita coisa. $\varepsilon u$ acho que as piores partes ali dentro foi no dia do aborto que eu vi o corpinho, que eu vi o bebê e na sexta-feira à noite quando eu recebi alta e o médico chegou para mim e falou assim: Olha, aborto você pode abortar hoje e amanhã ir trabalhar normalmente, não tem nada a ver isso. Eu vejo ele nos corredores e de vez em quando me dá vontade de esgoelar ele, mais fora isso tudo bem (O1ívia).

Quando há filho, há disponibilidade para a mulher; quando não há nenhum fruto, eventuais questões emocionais não são levadas em consideração. 
Por fim, outro profissional da equipe, sensibilizado com a situação de Olívia concedeu-lhe 15 dias de afastamento de suas atividades laborais. Entrevistei Olívia no dia em que retornou às suas atividades na Utin e era visível o sofrimento que estava vivenciado ao ter que cuidar de crianças tão pequenas.

Diante do abortamento de uma gravidez não planejada, outro sentimento que se fez expressamente presente foi o alívio.

Então eu pensei, graças a Deus que agora, porque eu não sabia como ia ser (Janaina).

Existem poucos trabalhos empíricos que abordam os aspectos emocionais das gestantes em estudo realizado com mulheres em situação de abortamento. Broemer e Mariutti (2003), Santos e colaboradores (2004) afirmam que a experiência do abortamento é permeada por grande dor tanto fisiológica quanto existencial; isso é mais potencializado nas mulheres que haviam planejado a gestação.

Um outro achado importante foi a constatação de que a experiência do abortamento traz para as mulheres preocupação com seus próprios corpos. Essa preocupação está diretamente associada às possíveis sequelas do abortamento, como por exemplo o medo fantasioso de não poder ter uma nova gestação. Por último, as mulheres que experimentaram um abortamento relataram o desejo de reverem seus projetos de vida.

Eu acho que esse aborto que tive serviu para eu ver o que estava fazendo comigo, porque eu estava fazendo tudo errado, tomava o comprimido errado, sem querer ficar grávida mais também não usando método nenhum. [...] acho que a minha cabeça abriu agora (Joice).

Psicologicamente muda tudo, eu não consigo ser mais a pessoa que eu era antes, qualquer coisinha eu choro, eu não fico bem. O que passa na minha cabeça é que eu poderia ter tido, porque a gente tava bem, eu gostava dele, e poderia ter tido. Só que ele não quis. Não assim, que "eu" não queria, só que sem trabalhar não tinha como eu ter. Eu não queria ter esse filho sozinha, sem um apoio, sem uma presença masculina do seu lado, porque é difícil. Eu nunca tive ninguém por perto, em todas as minhas relações eu não dou sorte. $\mathrm{O}$ que pode mudar é que agora eu posso trabalhar, pois antes eu não conseguiria. Mas por isso que eu tomei essa decisão também, porque eu preciso trabalhar, eu preciso ocupar a minha cabeça. (Helena).

Pattis (2001) afirma que um abortamento tende a ser um evento tão importante na vida de uma mulher que pode mudar o curso de sua existência, propendendo a considerar-se um rito de passagem.

\section{O Atendimento nos Serviços de Saúde}

Dor, cólica, sangramento. Esses são os sintomas que, no geral, fizeram com que as mulheres buscassem atendimento nos hospitais. Às vezes elas buscavam atendimento em outros hospitais públicos e privados antes de procurarem por atendimento no Hucam. Mas esses serviços, ao prestarem o primeiro atendimento, em alguns casos, não medicavam a mulher. Com dor e sangramento, ela era orientada a voltar para sua casa e esperar por um sangramento maior ou dirigir-se a clínicas de imagem, a fim de que realizasse exames de USG, para que o médico constatasse o óbito fetal e, a partir disso, prosseguisse com o tratamento. Disso surgia um processo de peregrinação em busca da realização do exame de USG que os hospitais públicos não disponibilizam e que custam em média R\$ 50,oo. Sem esses exames o atendimento, a medicação e a internação não seriam efetuados.

[...] quando chegou lá, o médico me atendeu e falou comigo que estava sangrando, mas que era pra voltar pra casa, se piorasse, para que no outro dia voltasse, aí voltei para casa, né? Sangrando, voltei para casa [...] eu achei bom quem me atendeu, falou direitinho, conversou comigo [...] que para fazer uma curetagem, para me atender direitinho eu tinha que ter um ultrassom, né? Pra ver se tinha, aí eleolhou e falou assim: Olha, o útero tem um lado que está aberto, o outro está fechado, o bebê pode estar no fechado, então a gente não pode mexer porque, porque não tem certeza, o certo seria se você tirar um ultrassom e vir com o ultrassom, como que eu ia fazer um ultrassom no sábado? Aí ninguém sabia onde tirava la ultrassonografial e eu sentindo dor, sentindo dor, 
cheia de dor [...] ninguém passou [pausa], aí eu falei bem assim com ele, [pausa]: Doutor, eu estou sentindo dor, ele falou assim: Mas eu não posso fazer nada, não posso fazer nada, porque você não tem um ultrassom aqui (Márcia).

Os motivos que fizeram com que as mulheres procurassem atendimento no Hucam foram os mais variados: algumas alegaram já terem procurado atendimento anteriormente no hospital, para o nascimento de seus filhos ou porque essa Unidade hospitalar se situa nas imediações de suas residências. Outras foram encaminhadas por outros serviços, como as UBSs, quando o caso da mulher era mais complexo e por outros hospitais da capital, por faltarem vagas para a assistência e internação.

Elen conhecia a mãe de um dos médicos do setor, e Olívia, como funcionária do hospital, pediu que sua superior interviesse na maternidade, a fim de garantir uma vaga para o atendimento imediato.

Uma amiga da igreja, e ela conhecendo uma outra pessoa, dentro da igreja também, cujo filho é um dos diretores de hospital, me indicou o Hospital das Clínicas (Hucam) e pediu pra que eu fosse para láno dia seguinte, 7 h da manhã, que eu fosse direto [...], porque ele ia me internar e ia fazer o procedimento (Elen).

As Clínicas (Hucam) estavam em greve e lá tava em superlotação e que eu precisava fazer logo, mas que eu não podia fazer lá, eu poderia fazer dali a três dia, mas o meu caso era grave; aí ele me encaminhou para cá e, como eu trabalho aqui também, eu vim para cá; eu cheguei, aí a chefe da enfermagem do serviço onde trabalho chamou a enfermeira que trabalha na obstetrícia, pra conversar, aí veio a enfermeira e chamou um médico para conversar, aí ele falou que era grave, que tinha que fazer circlagem logo, se não ia perder o bebê. Aí logo depois disso uns 10 ou 15 minutos, eu já estava na mesa para fazer a cirurgia (Olívia).

Com relação ao acesso à enfermaria, as mulheres foram unânimes ao afirmar que foi fácil entrar no hospital e que ao alegarem que necessitavam de atendimento, da portaria eram imediatamente encaminhadas para o serviço. Ao chegarem ao hospital em busca de atendimento, as mulheres em situação de abortamento provocado rompem a muralha da solidão e tornam público um problema de cunho privado (Arendt, 1975).

Embora o acesso, nesse caso representando o ato de ingressar (Houaiss, 2001), entrar na maternidade seja muito fácil, não significa a garantia de um acesso que, segundo Donabedian (2003), corresponde à facilidade de obter cuidados de saúde. O tempo de espera desde a chegada até o atendimento variou de acordo com a quantidade de mulheres que precisavam de atendimento.

Márcia afirma ter esperado o dia todo; somente no início da noite recebeu o primeiro atendimento. E o pior: foi encaminhada a voltar para casa e a retornar no dia seguinte.

Aídemorei [pausa], nossa, foi o dia todo [...] aí eu fiquei lá o dia todo [...] (Márcia).

No primeiro atendimento, pergunta-se à mulher se ela fez alguma coisa para provocar aquele abortamento. Das quatro mulheres que tiveram o abortamento provocado, duas relataram ter falado a verdade no primeiro atendimento. Helena provocou o abortamento e chegou ao hospital com infecção. Durante a primeira consulta com o profissional, não se sentiu à vontade para falar que havia usado Citotec ${ }^{\circledR}$. Diz ter sentido medo de ser presa ou de o médico brigar e, por isso mesmo, sendo indagada, negou o fato.

A clandestinidade na qual se encontra a experiência do abortamento deixa as mulheres privadas (Arendt, 1975) de seu direito à saúde integral, no que tange ao exercício dos direitos reprodutivos, bem como não têm satisfeitas as suas necessidades de saúde. É no hospital que as mulheres, ao burlarem a norma social, denunciam que sua autonomia reprodutiva não está sendo exercida e ficam expostas a toda quantidade e qualidade de julgamento por parte dos profissionais, tornando-se mais uma vez vulneráveis e à mercê da boa ou da má conduta do profissional que as atendem.

Por medo, porque eu sei que médico, entendeu? Com certeza, isso aí é proibido, entendeu? Por lei. $\varepsilon$ eu sei se eu contasse entendeu? Eles iam brigar comigo, iam acharruim, com certeza. No outro dia que já tinha acontecido tudo, aí fizeram exame, eu já tinha morrido de dor, já tinha acontecido o aborto (Helena). 
Flávia foi, sem ter sido examinada e medicada, encaminhada para fora do hospital, a fim de se realizarem mais exames. Márcia descreveu o atendimento como ruim, negligente e não resolutivo.

Ele nem me examinou e falou para eu fazer o teste de gravidez e para fazer a USG. Aí eu fui, falei com ele que eu tinha começado a sangrar, que estava com dor e ele [médico] falou que era para eu fazer o exame e pronto (Flávia).

[...] Me senti um lixo, né? Me sentia um pacote de lixo, joga pra um, joga pra outro, joga para um, parecia uma brincadeira, uma jogava pra outra, ficou assim [pausa], um jogo assim, é um empurra-empurra, um empurra pra outro e ninguém queria fazer nada (Márcia).

O SUS, num de seus pilares, afirma que a assistência seja equitativa e universal. Contudo, percebemos que a interação entre os médicos e as mulheres não é muito adequada. E pode-se afirmar que, embora não diretamente em ações violentas (Boulding, 1981), a assistência pode ser considerada violenta e discriminatória, pois a maior parte das mulheres entrevistadas não foram atendidas conforme preconização do Ministério da Saúde.

Arendt (2001) afirma que a violência é instrumental, ou seja, é um meio que necessita de orientação e justificação dos fins que persegue. Para ela, "[...] a violência multiplica, com instrumentos que a tecnologia fornece de maneira cada vez mais exponencial, o vigor individual. Por isso, a forma externa de violência é o um contra todos. E esta nunca é possível sem instrumentos".

Ou seja, podemos utilizar o conceito de privação (Arendt, 1975), no atendimento às mulheres em situação de abortamento. A assistência seria em si o instrumento de tecnologia, isto é, uma vez negada às mulheres, a assistência que auxiliaria na manutenção de suas vidas exprime o pensamento geral de que elas devem ser punidas por terem provocado o abortamento e, por isso, ficam sem o atendimento necessário e adequado.

Helena diz ter se sentido humilhada durante o processo de internação. Afirma que suas demandas não eram atendidas pelos profissionais que estavam cuidando do seu caso. Com dor, sem medicamento, e após ter sido negligenciada pela equipe de enfer- magem, teve a expulsão do feto no banheiro, onde foi amparada por outras mulheres, que, solidárias com seu sofrimento, a ampararam, evitando uma queda após o desmaio.

Eu tava sangrando e o médico falando que eu não estava. Eu tive que tirar o absorvente, as meninas que estavam no quarto comigo e tinham ganhado os nenéns, né?, não sabiam o que eu tinha, né? Poxa, e ficaram horrorizadas. Eu passei por maus bocados aqui. Isso foi no domingo da semana passada. Aí eu tirei o [...], me colocaram no soro, eu tirei o absorvente, aí eu mostrei. Aí ele me perguntou: Cadê o sangue aqui. Aí eu mostrei, tá aqui oh. Eu baixei assim a roupa para ele ver, aqui, aqui e ele, eu não tô vendo não, pegou, virou as costas e saiu. Aí a menina veio e me ajudou, colocou o absorvente na sacola e me disse para assim que ele viesse de novo para eu mostrar para ele o sangue. (o aborto) foi no quarto mesmo onde eu estava. Tinha uma outra paciente do lado, que assistiu tudo, e [...] foi ali, do lado. Muita humilhação, eu me senti humilhada, entendeu, porque eu não tive atendimento, eu tive um sofrimento, sozinha na cama, as meninas não conseguiram dormir a noite, entendeu? Elas, né, não sabiam o que é que eu tinha entendeu, e eu tive o aborto ali mesmo (Helena).

Com relação aos procedimentos obstétricos, a curetagem foi o segundo mais realizado nos serviços de saúde do SUS, superado apenas pelos partos normais (Brasil, 2005). De acordo com Shenk (2007), no ano de 2006 foram registrados $220 \mathrm{mil}$ casos de curetagem uterina, após abortamento nos hospitais do SUS. O MS preconiza que a forma de esvaziamento uterino seja discutida com a mulher. Neste estudo, percebemos que essa possibilidade de escolha não é discutida entre profissionais e mulheres. 0 profissional que a atende é quem determina o procedimento e somente cita o método que será utilizado. As narrativas das mulheres indicam o total despreparo no qual elas são encaminhadas para o procedimento, bem como as fantasias e expectativas que a orientação não dada de forma adequada pode provocar no imaginário da mulher.

[...] Me colocaram no soro, passaram lá um negócio que ele falou o nome mais agora eu esqueci, 
enfiaram um aparelho que abre igual o que usa para fazer preventivo e falou que eu ia sentir uma espetadinha, depois ele me falou que eu ia sentir uma dorzinha, só que não foi uma dorzinha não, foi uma dorzona, era como se tivesse arrancando o útero para fora (Alice).

[...] Não, não explicou (o procedimento), e nem eu sei, e queria até saber e até hoje estou sem saber (risos). Aí acordei e estava em outra sala já e estava esperando o efeito da anestesia passar, para ver que reação eu ia ter. Foi desse jeito (Lurdes).

Flávia e Olívia reclamam do atendimento que receberam no momento da curetagem. Os profissionais às vezes se comportam de maneira não profissional, fazendo brincadeiras com a mulher que, ansiosa, numa situação incomum na sua vida, sentem-se inseguras quanto ao procedimento a que está sendo submetida.

Olha, quando foram tirar meu sangue, ficaram rindo, eu atéfiquei nervosa, porque ficaram falando: "Você está fazendo errado, não é assim não". Não sei se estavam me distraindo, eu achei que elas estavam brincando, fazendo brincadeira. Aí foi, tiraram o sangue, me levaram para dentro, aí eu tomei a injeção e dormi (Flávia).

Ele foi muito grosso, muito ignorante assim, ele não me falou nada direito. Mas aí eu fiz assim mesmo a curetagem e eles me falaram que seis horas depois eu poderia ir para a minha casa; aí eu fui; à noite ele veio, e eu pedi atestado porque fiquei a semana toda, e eu tinha que levar para o serviço, aí ele falou que não tinha nada a ver isso, que eu podia ter perdido o filho em um dia e no outro ir trabalhar, porque não tinha nada a ver isso (Olívia).

Depois da curetagem, a história é outra. Já mais tranquilas com o fim da dor e não correndo mais riscos, as mulheres passam a ser medicadas, recebem alimentação e são atendidas mais de perto pelos médicos residentes, que são, na sua maioria, muito cuidadosos com as pacientes internadas. Após o procedimento, o sentimento predominante é de alívio, uma vez que não tiveram complicações e tiveram seu problema de saúde praticamente resolvido. 0 fato de ter recebido o atendimento, ter sido internada e ter resolvido o problema, praticamente produzia uma "amnésia" nas mulheres que esqueciam a peregrinação e as situações que tiveram que enfrentar até o momento e, por isso, muitas classificaram, no geral, o atendimento que haviam recebido como bom, ou seja, tiveram de certa forma respeitados os seus direitos reprodutivos.

Olha, depois que está lá dentro o atendimento é outro, né? Ah, foi bom, depois que entrei lá dentro os enfermeiros te olhando [...] (Márcia).

$\varepsilon$, conseguido uma vaga, entendeu? Conseguido seré [...] resolvido o problema, entendeu, foi muito bom, porque eu saí daqui com vida, eu poderia ter saído morta, pelo que estava acontecendo dentro de mim, eu podia morrer a qualquer momento, eu podia pegar uma outra infecção, e tal, então isso foi bom [...] (Rafaela).

Com relação ao estabelecimento de vínculo entre o profissional e as mulheres, perguntamos a elas se algum profissional havia discutido se estavam pensando em uma nova gestação e se precisavam de orientação, para evitar, caso não desejassem, que isso acontecesse. Todas foram unânimes ao afirmar que nenhum profissional da equipe havia conversado sobre os métodos contraceptivos e sobre sua saúde reprodutiva, bem como os exames anatomopatológicos do material coletado durante o processo de abortamento ou durante a curetagem e que poderiam identificar os motivos que levaram à perda gestacional.

Também perguntamos se alguém da equipe havia conversado sobre a perda gestacional, enfocando principalmente os sentimentos que essa perda estava provocando, bem como buscar a reconstrução da história dessa gravidez e o caminho de sua percepção até à perda. Todas as mulheres também foram unânimes ao afirmar que nenhum profissional havia perguntado como elas estavam se sentindo. Eles perguntavam o que havia acontecido e não como elas estavam se sentindo diante do que tinha acontecido. Informaram que esta pesquisadora fora a única pessoa que lhes perguntou sobre essas questões.

Com relação ao atendimento prestado pelos profissionais médicos, as opiniões são variadas do positivo ao negativo, dependendo da forma como o problema foi resolvido e do profissional que atendeu a mulher. Se o profissional foi sensível, solidário 
diante do sofrimento dela, o atendimento será classificado como bom, mas se ele não conseguir acolher a demanda da paciente, negligenciado-a, o atendimento será descrito como ruim.

Eu achei que ele não me atendeu direito, e que estava com má vontade de me atender, as meninas me falaram: Vocênão está com exame na mão, ele não vai te atender, não vai passar medicamento para você, ele vai te enrolar e mandar você fazer o exame (Flávia).

Os médicos trataram bem, até brincavam com a gente (Lurdes)

Cabe ao profissional que atende mulheres em situação de abortamento, de acordo com Brasil (2005), orientá-las sobre o planejamento familiar, ofertando contraceptivos, no caso dos abortamentos provocados, e nos casos dos abortamentos espontâneos esclarecê-las sobre o que de fato ocorreu para que houvesse a perda dessa gestação e oferecer assistência, caso elas quisessem tentar engravidar novamente. É obrigação do profissional de saúde orientar as mulheres, a fim de que melhorem seu entendimento do próprio corpo, da sua doença, de suas relações com o meio social e com a capacidade de cada uma instituir normas que ampliem as possibilidades de sobrevivência e qualidade de vida (Canguilhen, 2006).

Como tivemos a oportunidade de entrevistar novamente três mulheres, percebemos como elas estavam lidando com a situação praticamente 2 meses após o evento do abortamento. Constatamos que o espaço da pesquisa foi considerado um lugar de reflexão e de assistência, pois, nesse momento, foi dada voz às mulheres; elas puderam relatar sua experiência, viver um pouco da sua dor, relatar os sentimentos que nenhum profissional lhes deu oportunidade de expressá-los.

Ah, me ajudou a encarar a vida com outros olhos, a reerguer minha cabeça, entendeu? Porque é muito bom vocêfalar do que você está sentindo, $e$, assim [...] é,falar pra alguém que não te conhece, éum desabafo, né? Quevocê sente, éum pouco de peso que você tira dos seus ombros também [...] Eu me senti mais aliviada [...] (Rafaela).

Faz porque, você passar por tudo isso e ter com quem conversar, com quem se abrir, com quem falar do que aconteceu, eu acho que melhora um pouco. Melhora porque o seu sofrimento ameniza um pouquinho em você partilhar isso com alguém, e, melhorou pra mim, porque eu saí daí me sentindo melhor, e o apoio que eu tive, né?, de ouvir uma pessoa dizendo que eu posso ter outro filho, que eu posso saber o que aconteceu com ele, e que é só me cuidar que eu posso ter outro filho (Elen).

\section{Ah foi! Foi bem porque eu estava ali angustiada, deprimida (Márcia).}

Perguntar às mulheres como elas se sentiram após o abortamento nos indicou que, embora os aspectos físicos tenham sido solucionados, os aspectos emocionais não haviam sido elaborados e elas ainda relatavam os mesmos sintomas emocionais que descreveram no momento da primeira entrevista. Defey e colaboradores (1985) afirmam que após a perda da gestação a mulher muitas vezes demonstra-se envergonhada, como se tivesse falhado como mãe, como se um pedaço de seu corpo tivesse sido perdido. Essa experiência traz consigo uma dor que persiste por muitos meses após o evento da perda. Esses sentimentos não expressos podem provocar outras complicações e até mesmo desenvolver distúrbios emocionais (Deutsch, 1952; Aray, 1998; Szejer e Stewart, 2002).

\section{Considerações Finais}

Percebemos que as necessidades de saúde das mulheres - no que se referem aos aspectos reprodutivos - não são efetivamente satisfeitas pelo sistema de saúde, desde a assistência primária, qual seja, a cobertura contraceptiva às mulheres em idade reprodutiva até a interrupção da gravidez quando essa for de escolha e ou necessidade da mulher.

Relativamente às mulheres, observamos que, embora conheçam e enumerem as possibilidades contraceptivas, muitas relataram que no mês em que engravidaram não estavam fazendo uso ou não estavam fazendo uso adequado de métodos contraceptivos.

Observamos que o fato de a gravidez ser planejada ou não é um grande estimulador para a prática de um abortamento provocado ou não. A situação conjugal, as condições socioeconômicas e a existência de 
outros filhos pequenos que demandam cuidados foram fatores muito importantes na determinação em manter ou não a gestação. Acerca da vida conjugal, o fato de ter ou não um parceiro não foi impeditivo da realização do abortamento. Embora a maioria das mulheres entrevistadas tenha afirmado vivenciar uma relação conjugal estável, não foi observada a presença física nem simbólica do parceiro durante o evento do abortamento, o que nos indica que o abortamento é um ato solitário, independente de ter sido provocado ou não.

Da análise dos dados obtidos, observamos que a assistência prestada pôde ser considerada violenta e discriminatória nos dois sentidos: tanto para as mulheres que fizeram o abortamento, indo contra a norma legal e social vigente, como para aquelas que sofreram um abortamento espontâneo, uma vez que, segundo as próprias mulheres, elas eram deixadas na espera sem atendimento imediato. Pode se apreender dessas situações que a assistência reflete o papel social da mulher como intimamente ligado à sua capacidade de reproduzir.

Outro fator importante e que dificulta a assistência de maneira adequada está relacionado à estrutura do serviço de atendimento. Com relação à infraestrutura, há inúmeros problemas de ordem física e ordem material. Os leitos não são adequados, não permitem que as mulheres tenham nem conforto nem privacidade. As mulheres que acabaram de ter um abortamento ficam acomodadas junto com as puérperas e não se leva em consideração o fato de elas terem acabado de perder uma gestação, independentemente de essa perda ter sido espontânea ou provocada.

Sobre a assistência à saúde da mulher em situação de abortamento, verificamos inúmeras falhas: ausência de adequação das tecnologias de todos os tipos, desde os estruturais, como exames laboratoriais, USGs e instrumentos para a realização de procedimentos, até aos humanos, como acolhimento, vínculo, responsabilização sanitária e implicação profissional.

Não pôde ser notada diferença significante na assistência que é prestada às mulheres em situação de abortamento espontâneo e de abortamento provocado. Tampouco se puderam perceber diferenças no atendimento às mulheres que se encontravam noutras circunstâncias, tais como na iminência de abortamento.

Diante disso, percebe-se que a assistência não integra nem se ocupa das reais necessidades de saúde da mulher em situação de abortamento. Questões íntimas, subjetivas, pessoais, não são contempladas e a mulher na sua integralidade não é vista, não é acolhida nem é tratada. As questões emocionais que, caladas, podem provocar sequelas não visíveis pelo diagnóstico corpóreo, tendem a ser perpetuadas e não acolhidas pelos serviços, embora os protocolos assistenciais em sua maioria tutelem a necessidade da assistência em saúde também das possíveis sequelas psíquicas.

As pesquisas podem contabilizar os números das vidas ceifadas em decorrência das complicações desse problema de saúde que é social e político. Mas devem, também, indicar as reais necessidades de saúde que as mulheres nessa situação demandam. Além disso, devem nortear as políticas públicas e as políticas de gestão em saúde, a fim de que a assistência prestada às mulheres nessa situação não se baseie em somente tratar das consequências e sequelas fisiológicas dessa doença, mas, também, das consequências simbólicas, emocionais, que números não são capazes de mensurar.

\section{Referências}

ARAY, J. Aborto: estudio psicoanalítico. Caracas: Monte Ávila, 1998.

ARENDT, H. A condição humana. Rio de Janeiro: Forense Universitária, 1975.

ARENDT, H. Sobre a violência. Rio de Janeiro: Relume-Dumará, 2001.

BECKER, W. S. Método de pesquisa em ciências sociais. São Paulo: Hucitec, 1999.

BORN, L. et al. Trauma e o ciclo reprodutivo feminino. Revista Brasileira de Psiquiatria, São Paulo, v. 27, 2005, p. 65-72. Suplemento 2.

BOULDING, E. Las mujeres y la violencia social: In: JOXE, A. (Org.). La violencia e sus causas. Paris: Unesco, 1981. p. 33-45.

BOURDIEU, P. A miséria do mundo. Petrópolis: Vozes, 2003. 
BRASIL. Ministério da Saúde. Secretaria de Atenção à Saúde. Departamento de Ações Programáticas Estratégicas. Área Técnica de Saúde da Mulher. Atenção humanizada ao abortamento: norma técnica. Brasília, DF, 2005.

BROEMER, M. R.; MARIUTTI, M. G. A mulher em situação de abortamento: um enfoque existencial. Revista da Escola de Enfermagem da USP, São Paulo, v. 37, n. 2, p. 59-71, 2003.

CANGUILHEM, G. O normal e o patológico. Rio de Janeiro: Forense Universitária, 2006.

CICOUREL, A. Teoria e método em pesquisa de campo. In: GUIMARÃES, A. Z. Desvendando máscaras sociais. Rio de Janeiro: Francisco Alves, 1990. p. 87-122.

CORTES, S. M. V. Técnicas de coleta e análise qualitativa de dados. In: Pesquisa Social Empírica:métodos e técnicas. Cadernos de Sociologia/ Programa Pós-Graduação em Sociologia. Porto Alegre:PPGS/UFRGS. v. 9, p. 11-47, 1998.

DEFEY, D. et al. Duelo por un niño que muere antes de nacer: vivencias de los padres y del equipo de salud. Centro Latinoamericano de Perinatlogia y Desarrollo Humano (CLAP). Publicacion científica CPAP 1086. Montevideo: OPS-OMS. Diciember, 1985 .

DEUTSCH, H. La psicologia de la mujer. Buenos Aires: Losada, 1952.

DONABEDIAN, A. An introduction to quality assurance in health care. New York: Oxford University Press, 2003.

DUARTE, G. A. et al. Perspectiva masculina acerca do aborto provocado. Revista de Saúde Pública, São Paulo, v. 36, n. 3, p. 271-277, 2002.

ESPÍRITO SANRO, P. F.; VIEIRA, E. M. Percepções sobre o aborto: um estudo com profissionais de saúde. Revista de Enfermagem da UFPE, Recife, v. 1, n. 2, p. 180-186, 2007.

FAÚNDES, A.; BARZELATTO, J. O drama do aborto: em busca de um consenso. Campinas: Komedi, 2004.
FRANÇA, G. V. Aborto legal e aborto criminoso. In: Medicina legal. Rio de Janeiro, Guanabara Koogan, 1995. p. 174-181.

GESTEIRA, S. M. A.; BARBOSA, V. L.; ENDO, P. C. O luto no processo de aborto provocado. Acta Paulista de Enfermagem, São Paulo, v. 19, n. 4, p. 462-467, 2006.

GRIGOLETTI, L. V. S. A influência da ultrassonografia na representação do filho imaginário - filho real. Psico, Porto Alegre, v. 36, n. 2, 149-157, 2005 .

HOUAISS, A.; VILLAR, M. Minidicionário Houaiss da língua portuguesa. Rio de Janeiro: Objetiva, 2001.

LÜDKE, M.; ANDRÉ, M. E. D. A pesquisa em educação: abordagens qualitativas. São Paulo. EPU, 1986.

MONTEIRO, M. F. G.; ADESSE, L. Magnitude do aborto no Brasil: uma análise dos resultados de pesquisa. Rio de Janeiro: Instituto de Medicina Social, 2007. Disponível em: <http://www.ims. uerj.br/downloads/ipas_ims_seminario_aborto.pdf Acesso em: 25 jun. 2007.

OLIVEIRA, E. M.; SCAVONE. L. (Org.). Trabalho, saúde e gênero na era da globalização. Goiânia: AB Editora, 1997.

OLIVEIRA, E. M. et al. Atendimento às mulheres vítimas de violência sexual: um estudo qualitativo. Revista de Saúde Pública, São Paulo, v. 39, n. 3, p. 376-382, 2005.

PATTIS, E. Aborto, perda e renovação: um paradoxo na procura da identidade feminina. São Paulo: Paulus, 2001.

POPE, C.; MAYS, N. Pesquisa qualitativa na atenção à saúde. Porto Alegre: Artmed, 2006.

QUAYLE, J. 0 abortamento espontâneo e outras perdas gestacionais. In: ZUGAIB, M.; TEDESCO, J. J. (Org.). Obstetrícia psicossomática. São Paulo: Atheneu, 1997. p. 132-153.

QUEIROZ, M. I. P. Variações sobre a técnica de gravador no registro da informação viva. São Paulo: T. A. Queiroz, 1991. 
RODRIGUES, M. M. L.; HOGA, L. A. K. Homens

e abortamento espontâneo: narrativas das experiências compartilhadas. Revista da Escola de Enfermagem USP, São Paulo, v. 39, n. 3, p. 258 267,2005 .

SANTOS, A. L. D.; ROSENBURG, C. P.; BURALI, K. O. Histórias de perdas fetais contadas por mulheres: estudo de análise qualitativa. Revista de Saúde Pública, São Paulo, v. 38, n. 2, p. 268-276, 2004.

SHENK, K. O abortamento inseguro atinge severamente o Brasil. Revista de Saúde Sexual e Reprodutiva, Rio de janeiro, n. 31, set./out. 2007. Disponível em: <http://www.ipas.org.br/revista/ seto7.html\#dois $>$. Acesso em: 20 set. 2007.

SOIFER, R. Psicologia da gravidez, parto e puerpério. Porto Alegre: Artes Médicas, 1986.

SZEJER, M.; STEWART, R. Nove meses na vida da mulher: uma abordagem psicanalítica da gravidez ao nascimento. São Paulo: Casa do Psicólogo, 2002.

THIOLLENT, M. Critica metodológica, investigação social e enquete operária. São Paulo: Polis, 1980. 